\title{
Ashurbanipal's Enduring Archetype: Thoughts on the Library's Role in the Future
}

\section{Peter Briscoe, Alice Bodtke-Roberts, Nancy Douglas, Michele Heinold, Nancy Koller, and Roberta Peirce}

The library's basic functions have displayed remarkable continuity for more than two millennia despite major changes in communications media. On the eve of another such change-from printing to widespread electronic publishing - this article reexamines and projects into the future the library's fundamental role as a social institution. An emerging information industry is strongly challenging the library. However, it appears unlikely that the "for-profit" sector could ever permanently preserve mankind's records. The library's longevity will depend upon how resolutely it extends rather than abandons its traditional functions within an electronic environment.

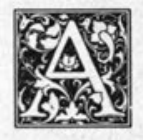

s a social institution the library has existed for at least twentysix hundred years-three times longer than the university. Significantly, the first known libraryAshurbanipal's in Nineveh, which flourished in the seventh century B.C.-performed the same basic functions as a library today. It (a) assiduously collected written texts from throughout the known world; (b) cataloged and classified them by subject; (c) conserved records by recopying; (d) used them to answer the king's questions (reference); and, (e) provided him and a few other high officials with something to read (circulation). ${ }^{1}$

Functionally, the library has been well defined and stable from its outset. History records changes in the locations, numbers, and sizes of libraries and in their types of clientele, sources of funding, subject specializations, prevailing media, technologies, and practices. But the institution's fundamental work seems to have remained the same. This should be kept in mind whenever one thinks about the library of the future. Nevertheless, a number of observers believe that the library will undergo drastic changes within the next twenty to thirty years. The most outspoken, F. W. Lancaster, flatly states that "I see little future for the library" and predicts it will be both "disembodied" and "bypassed" by technological developments. $^{2}$

\section{THE ENVIRONMENT}

Three environmental trends do appear likely to call into question both the nature of the library as an institution and the role of the librarian. The first is the growth of an information industry, which has been described in publications by Leigh Estabrook, Howard Resnikoff, Anita Schiller, and Herbert I. Schiller. ${ }^{3}$ The information industry has emerged from the computer, telecommunications, and reprographic sectors. It reaches beyond the manufac- 
ture of machines and systems for data processing to actual ownership and control of information. Already dominated by multinational corporations, the industry advocates the commercialization of much governmental publishing as well as publicly financed research. It is a potential competitor of both universities and libraries; among other things, it will repackage their services as information products. Libraries are being used to prepare new markets for the information industry. In the future we can expect more and more marketing criteria, as opposed to cultural or social criteria, to influence information access and publishing. The new industry considers information to be just another basic commodity, in spite of the fact that it possesses highly unusual economic properties.

The second trend is the proliferation of computer terminals in homes and offices. This will allow people to access information resources remotely and conceivably to bypass the library if equal or better alternatives exist.

The third trend is a gradual shift in publishing from print to electronic media. As Peter Briscoe stated in a 1981 article on electronic publishing, the change is due to “1) rising costs of book and journal manufacturing; 2) need to decrease the time required for publishing; 3 ) need to control and provide access to ever increasing amounts of data and information; and 4) recognition of some unique and special attributes of electronic media (e.g., interaction between the user and the information system; Boolean search logic, continuous updating and exceptional graphic displays including superimpositions, movement, 3-dimensional rotation, and variable colors). ${ }^{\prime 4}$

Many of today's printed publications also exist in machine-readable form. Indeed, in more cases than not, the former are generated from the latter. We can expect the dual-media approach to continue for a long time-at least until an inexpensive electronic reading device with a book's portability and ease of use is perfected. After that, true electronic publishing (online, downloaded, or packaged) will probably begin to prevail. We should bear in mind, however, that technologies generally overlay rather than eliminate each other. Daniel Boorstin has commented that "People expected print to displace the use of memory, the telephone to displace the postal system, the automobile to displace the bicycle and television to displace radio, movies and books. But that's not what happens. New technologies transform the use of old ones. They don't replace them. ${ }^{\prime \prime 5}$

\section{THE LIBRARY AS}

\section{AN INSTITUTION}

There seems to be some question about whether the library of the future will be an institution of knowledge or a broker of information. The words information and knowledge are often used interchangeably, but for this discussion they are different. The biologist Paul Weiss, in an article entitled "Knowledge: A Growth Process," states that

Information is but the raw material, the precursor of knowledge. .... Knowledge emerges from the distilling, shaping, and integrating of the raw material into concepts and rules, and in the process of condensation and generalization, the number of bits of detailed information dwindles, rather than mounts. ${ }^{6}$

Daniel Boorstin, historian and current Librarian of Congress, is even more emphatic in an article entitled "Gresham's Law: Knowledge or Information?":

I would like to focus your attention on the distinction between knowledge and information, the importance of the distinction, and the dangers of failing to recognize it. ... .

While knowledge is orderly and cumulative, information is random and miscellaneous. We are flooded by messages from the instanteverywhere in excruciating profusion. In our ironic twentieth-century version of Gresham's law, information tends to drive knowledge out of circulation. The oldest, the established, the cumulative, is displaced by the most recent, the most problematic. The latest information on anything and everything is collected, diffused, received, stored, and retrieved before anyone can discover whether the facts have meaning.

Let us also define the terms institution and broker using Webster's Third:

Institution-a significant and persistent element (as a practice, a relationship, an organization) in the life of a culture that centers on a fundamental human need, activity, or value, 
occupies an enduring and cardinal position within a society, and is usually maintained and stabilized through social regulatory agencies. Broker-an agent middleman who for a fee or commission negotiates contracts of purchase and sale (as of real estate, commodities, or securities) between buyers and sellers without himself taking title to that which is the subject of negotiation and usually without having physical possession of it.

Probably the most critical strategic decision a library will make in the next ten to twenty years is its definition of itself. As an institution it has been unique for twenty-six hundred years; as a broker, it will likely join a mob. Information and knowledge are not mutually exclusive concepts. They are the extremes of a continuum, or the beginning and end of a process. Knowledge subsumes information, but the converse is not true. By extension, a knowledge institution can include an information-brokering function, but not the other way around.

Why is this? Let us look at their differences. By definition, a broker neither takes title to nor usually physically possesses the commodity it negotiates. In the case of information, this would mean that someone else owns and controls the ultimate source-an archive, collection, or database. F. W. Lancaster's prediction that electronic publishing will disembody the library-i.e., eliminate the need for collecting-does not mean that the functions of collecting, archiving, or database maintenance would vanish. They couldn't. The functions would simply transfer to, and most likely be centralized in, other organizations-generally profitmaking organizations.

Society's need to collect, preserve, and maintain the integrity and availability of records in all media is permanent, which is why it makes perfect sense for a public institution to be given the responsibility. Businesses can go bankrupt, merge, and be swayed by political and economic factors. And a business, no matter what it does, must ultimately be profitable. When the profit margin for a product or service declines, either a solution is found to stabilize or reverse the trend or the product is withdrawn. Even the most idealistic publishers do not reprint books that have stopped selling. Consider then, that since records of information and knowledge never cease to grow, average use per record must steadily decline. In the long run, profit cannot be made from permanently storing records. Some records must be purged. Any permanent collection/archive/database of records can only exist in the not-for-profit sector. "Knowledgeinstitutions," says Boorstin, "do not pay the kind of dividends that are reflected on the stock market. They are sometimes called 'philanthropic', which means that they profit nobody except everybody and their dividends go to the whole community.",8

The problem with businesses keeping archives is classically illustrated by the American film industry. According to two articles in the Los Angeles Times, twentyone thousand feature-length films were produced in the United States between 1900 and 1951 . Half of them no longer exist. In addition, declares Robert Manby, president of RKO Pictures, "more than one-third of all films and television programs produced since 1950 are also gone." "The second article quotes Audrey Kupferberg, assistant director for the $\mathrm{Na}$ tional Center for Film and Video Preservation at the American Film Institute headquarters in Washington, D.C., as follows: "Thousands of films that are the most beloved by archivists and film scholars have been found only in the collections of private individuals. ... These film documents are very important to our cultural heritage. They just don't coincide with profits for the studios." Many losses are described, including this one: "Several film collectors interviewed for this article reiterated stories of how Universal Pictures destroyed all of its silent films in 1947 , without offering them to any of the local or national film archives.",10

Lately it has become fashionable to say that access to information, not ownership, is what is important. This is a dangerous oversimplification. Access always presupposes or depends on ownership-by some party. At present, libraries can more or less guarantee unrestricted, continuing, affordable, and integral access to records because they collectively own them. Research libraries in particular have a funda- 
mental responsibility to collect virtually all of recorded knowledge and make it available for use. Local self-sufficiency is not implied. This goal can only be achieved by coordinated, cooperative collection development. ${ }^{11}$ In the future, research libraries will collect databases just as seriously as they collect books today-and they will safeguard both.

However, safeguarding electronic publications will not be an easy matter. There are two sides to the problem, which this article will merely identify: maintenance of record integrity and physical preservation. To put it mildly, databases are extremely vulnerable to improper additions, deletions, and revisions. Security measures notwithstanding, they are inherently revisable, and thus conducive to plagiarism, forgery, fraud, censorship, and propaganda attempts. Briscoe's article "Electronic Publishing-Its Darker Side" provides additional analysis, including this observation:

With printed documents the greatest deterrent to forgery is the existence and wide dispersal of other copies, which can be produced to confirm or deny authenticity. There are also scientific methods of studying paper, ink, typefaces, handwriting, and other physical features of a document to establish its authenticity. Are there analogous methods for validating a data base, when data can be erased, added, or altered with the press of a button? We know that it is possible to break the external security of a data base system, or to have unscrupulous persons actually controlling the system (e.g., the $\$ 200$ million Equity Funding case of 1973). ${ }^{12}$

Downloading or depositing archival copies of databases in nonprofit, politically neutral, widely dispersed research libraries may still be a valid means of detecting and proving electronic forgeries.

In regard to preservation, newer media have severe problems. Their current longevity appears to be considerably less than that of pulp paper. Judith Michaelson reports in the Los Angeles Times (June 20, 1983) that "today virtually all production for film and television consists of color film in single-strip emulsion. Unlike the Technicolor three-strip process, experts say the single-strip film can fade irretrievably in as few as five years. ... Videotape's shelf life ranges from 5 to 25 years, essentially due to the constant changes in the chemical composition of magnetic tapes. ${ }^{113}$ Gordon R. Williams, in an article entitled "The Function and Methods of Libraries in the Diffusion of Knowledge," states that "Storage on magnetic tape, at least as of now, is quite impermanent. The records on many tapes less than a decade old are now frequently so dirty from print through, stray magnetic fields, impermanence of orientation, radiation, and other factors, as to be virtually unreadable. Records to be preserved for centuries will probably have to be transferred to a more permanent medium at some now-unknown cost, and this cost will have to be included in the balancing of choices. ${ }^{\prime 14}$ Even the very promising digital optical disk has an estimated archival life of only 10 to 30 years. ${ }^{15}$ So, like the scribes of Ashurbanipal, future librarians will recopy in order to conserve knowledge, but will use a laser instead of a stylus.

One thing is certain. Technology has already changed the traditional way in which libraries operate, and this trend will continue. But how it continues, what direction it takes, and how those in libraries apply available technology is up to them. Above all, librarians must not let technology be the dictator. The library needs to persist in its role as a knowledge institution-mankind's archive and encyclopedia-while providing the necessary services of an information broker: computer literature searching, information retrieval, and document delivery.

\section{PUBLIC POLICY AND ECONOMIC CHOICES}

National public policy on information is still unformed, in contrast to policy on antitrust, labor relations, and food and drugs. Without a doubt, it will receive enormous attention in the future, and librarians must get ready to engage in the debate. The Information Industry Association says that its primary goal is "to promote the development of private enterprise in the field of information and to gain recognition for information as a commercial product." ${ }^{16}$ But as Marc Porat points out, 
Information is unlike most other economic goods. The same piece of information can be simultaneously owned by two people without denying either the benefits of ownership. Certain types of information can be infinitely reproduced with very low resource costs. Information does not depreciate with use; to the contrary, certain types of information (theoretical knowledge) increase in value the more they are used. Informational services, unlike personal services, do not vanish when the service ceases. Also, unlike personal services, informational services can be stored in inventory.

The most serious characteristic of information is that it lends itself so poorly to the classical economic and legal concepts of property rights. One cannot easily own information, because the act of theft is difficult to detect and even more difficult to prove. As simultaneous ownership is possible, there is no clear way of claiming or proving sole ownership. ${ }^{17}$

The information industry may be trying to do something like bottle and sell air. Certainly it is "thinking big." But one wonders if its goals are compatible with a democratic society, dependent on a free flow of information and an educated, informed electorate. Everyone knows that "free" library services do not exist. These services are provided by taxpayers, tuition payers, philanthropists, and others. But "free access" has long existed. As Richard De Gennaro has said, "the arguments for pay libraries may be made in the name of economic theory, efficiency, or inevitable economic trends, but in essence it is a political idea, just as the concepts of free public library service or free public education are political ideas. ${ }^{\prime 18}$

After admitting this, it becomes easier to explore possible accommodations between the private and public information sectors. Governmental regulation will probably be needed.

First, broaden the depository principle. Copies of electronic publications derived from databases, or the databases themselves, should be deposited by law in regional library consortia or library utilities, as well as in the Library of Congress. This would ensure (1) database integrity, (2) physical preservation, and (3) public right to access. Recognizing the time value of information, it would be agreed that nonprofit libraries would access the databases at generally lower institutional rates for a certain period of time, after which the information would go into public domain.

Second, recognize in copyright law that fair use includes reuse. The information industry would like to charge a fee for every use that is made of its publications: every retrieval, every reading, every consultation, every printout. Such a pricing system can only have a chilling effect on creativity and research. As Richard S. Halsey says, "much scholarly inquiry must be leisurely, inefficient, nonlinear, superficially wasteful in the manner of its accomplishment. Because the cost of remote access is charged by the second, speculative behavior and 'time-outs' are disallowed." 19

On the other hand, traditional library economy is based upon reuse of publications-the more, the better. Reusability is not a trivial principle. The library should defend its right to circulate electronic publications that have been downloaded or printed out.

In any case, librarians must become sophisticated, knowing when it is costeffective to own rather than access information, or vice versa, and also when slower but cheaper methods of access are good enough for the intended use. Big library systems should certainly consider purchasing and mounting databases on their own.

One crucial policy issue remainswhether to charge user fees. If there is economic pressure for doing so now, that pressure will increase immensely as more and more publishing goes online. "The American Library Association asserts that the charging of fees and levies for information services, including those services utilizing the latest information technology, is discriminatory in publicly supported institutions providing library and information services." ${ }^{20}$ Students, faculty, and staff, upon admission or appointment to a university, for example, have every right to expect free access to information as a necessary condition of intellectual work. But here, as elsewhere, the solution does not lie in simply diverting currently budgeted funds (personnel, equipment, and books) into new areas, not while traditional areas show no decline in use and need. Some entirely new funding is necessary. Furthermore, as argued above, many of the 
assumptions of the information industry demand serious questioning, not budgetary acquiescence.

Public policy on information is gradually being formed. The question: will it be a liberal policy-will it even be nondiscriminatory? In the past one would have known exactly where librarians stood on such issues, but now many seem enthralled by a kind of technological deter- minism being promoted by the information industry. The glamour and novelty of automation are conducive to a substitution of means for ends. To keep things in perspective, librarians should remember that their ancient profession, in carrying out its mission, has comprehended and used many technologies, from clay tablets to computers.

\section{REFERENCES}

1. Mogens Weitemeyer, "Archive and Library Technique in Ancient Mesopotamia," Libri 6:217-38 (1956); A. Leo Oppenheim, "Assyriology-Why and How?" Current Anthropology 1:409-23 (Sept.-Nov. 1960).

2. F. W. Lancaster, "Future Librarianship: Preparing for an Unconventional Career," Wilson Library Bulletin 57:747-53 (May 1983). See also F. W. Lancaster, Laura S. Drasgow, and Ellen B. Marks, "The Changing Face of the Library: A Look at Libraries and Librarians in the Year 2001," Collection Management 3:55-77 (Spring 1979).

3. Leigh Estabrook, "Productivity, Profit, and Libraries," Library Journal 106:1377-80 (July 1981); Howard Resnikoff, "The Information Technologies and Institutions of Higher Learning," in Universities, Information Technology, and Academic Libraries: The Next Twenty Years, ed. Robert M. Hayes (UCLA, Lake Arrowhead Conference Center, December 13-17, 1981), p.127-212; Anita Schiller, "Shifting Boundaries in Information," Library Journal 106:705-9 (April 1, 1981); Herbert I. Schiller, Who Knows: Information in the Age of the Fortune 500 (Norwood, N.J.: Ablex, 1981).

4. Peter Briscoe, "Electronic Publishing-Its Darker Side," Technicalities 1:14 (July 1981).

5. Quoted in Edward B. Fiske, "First of the Three R's Isn't About To Go Down the Tube," RiversideEnterprise, September 9, 1983.

6. Paul Weiss, "Knowledge: A Growth Process," Science 131:1717 (June 10, 1960).

7. Daniel J. Boorstin, Gresham's Law: Knowledge or Information? (Washington, D.C.: Library of Congress, 1980), p.1-3.

8. Ibid., p.2.

9. Quoted in Judith Michaelson, "Push Is On to Preserve Film History," Los Angeles Times, June 20, 1983.

10. Dale Pollock, "Collectors: Film Heroes or Villains?" Los Angeles Times, September 16, 1983.

11. Paul H. Mosher and Marcia Pankake, "A Guide to Coordinated and Cooperative Collection Development," Library Resources \& Technical Services 27:417-31 (Oct.-Dec. 1983).

12. Briscoe, p.15.

13. Michaelson.

14. Gordon R. Williams, "The Function and Methods of Libraries in the Diffusion of Knowledge," Library Quarterly 50:74 (Jan. 1980).

15. William R. Nugent, "'Optical Disk Technology," in In Service to Scholarship: Minutes of the One Hundredth Meeting of the ARL (Scottsdale, Ariz., May 6-7, 1982), p.78; Surachai Suthasinekul, "Microfilm vs. Optical Disc as Storage Medium for Document Retrieval and Dissemination," in Communicating Information: Proceedings of the 43rd ASIS Annual Meeting 17:101-2 (1980).

16. Quoted in Anita Schiller, "Shifting Boundaries," p.706.

17. Marc U. Porat, "Communication Policy in an Information Society," in Communications for Tommorrow: Policy Perspectives for the 1980's, ed. Glen O. Robinson (New York: Praeger, 1978), p.35.

18. Richard De Gennaro, "Pay Libraries \& User Charges," Library Journal 100:366 (Jan. 15, 1975).

19. Richard S. Halsey, "Recall-Research-Renewal: A Message of Necessity for the University Library," in Future of Libraries: Panel Discussion by Librarians, Administrators, Faculty, and Students, Papers from the Millionth Volume Celebration (SUNY-Albany, September 24, 1982), p.23.

20. ALA Policy Manual, Section 50.4, in ALA Handbook of Organization 1984/85 (Chicago: American Library Assn., 1984), p.214. 